\title{
DESIGN OF STREAMING EDUCATION CONTENT ON ANDROID BASED MOBILE DEVICE FOR LONG LIFE E-LEARNING
}

\author{
Wahyul Amien Syafei \\ Communication \& Signal Processing Laboratory, Diponegoro University Semarang \\ Email: wasyafei@gmail.com
}

\begin{abstract}
This paper presents design of education content streaming applications on Android based mobile devices. It is kind of a learning media that utilizes Internet data services and mobile telecommunications device. The test results prove that the developed system can provide a visual and interactive learning media spontaneously over time (long life learning) and is not limited by space and time. The main component of the education system (task and teaching materials) has also been successfully applied.
\end{abstract}

Keywords: Education Content, Android, Mobile Device, E-Learning.

\begin{abstract}
Abstrak
Paper ini menyajikan desain aplikasi konten pendidikan berbasis streaming di perangkat Android. Ini adalah jenis media pembelajaran yang memanfaatkan layanan data internet dan perangkat telekomunikasi mobile. Hasil pengujian membuktikan bahwa sistem yang dikembangkan dapat memberikan media pembelajaran visual dan interaktif secara spontan dari waktu ke waktu (long life e-learning) dan tidak dibatasi oleh ruang dan waktu. Komponen utama dari sistem pendidikan (tugas dan bahan ajar) juga telah berhasil diterapkan.
\end{abstract}

Kata kunci: Konten Edukasi, Android, Perangkat Mobile, E-Learning.

\section{Introduction}

The development of e-learning methods is still bound by traditional pedagogy. Current system only used to upload assignments, and just a bit information or knowledge shared. It is caused by a lack of participation both of learners and educators. The lack of participation in this current educational e-learning system is because they tend to spend their time using mobile devices (Smartphone) than the computer.

There are so many studies shown that the effectiveness of learning using the Internet known as electronic-learning (e-learning) tend to be the same when compared to the conventional or classical learning, but a research by Quincy [2] prove that collaboration between intelligent learning system applications (Intelligent Tutoring System / ITS) in desktop compared to the mobile devices can provide more benefits for teachers and students. ITS on mobile devices have the potential to deliver educational materials to more learners and not limited to computer labs or traditional classroom, so we can reach the concept of "anytime and anywhere" learning. Research conducted by Quincy also mentions textual learning methods are less effective against the concentration of the learners.

This research's aim is designing a learning method streaming using mobile devices. The purpose is to change the paradigm of textually online learning by using a combination of textual and visual methods which more interactive. This application as an output of the research is built on the Android-based devices because it is easily expandable platform for mobile devices and the devices are widely used at this time.

\section{Streaming Education Content On Mobile Device}

Robby Robson [3] said that to adopt a technology in education requires two basic requirements, there were the technology must be made more effective teaching strategies and technologies must always be available and accessible. Streams Mobile Education is a breakthrough in the world of education as a means 
of learning using Internet technology and mobile telecommunications devices.

Online learning technology commonly take advantage of web technology, where the interaction is done by accessing a web page using the computer. Education on Mobile Streaming learning models were made between the place or environment using portable devices.

In this research, the educational system for mobile streaming applications planted in the Android mobile device in order to communicate with a web server. Through this system, educators can convey his ideas directly to students, and students can learn quickly, learn to interact and develop their knowledge.

\subsection{JSON (Javascript Object Notation)}

JavaScript Object Notation or JSON is format for data exchange such as XML. JSON is easy to understand because the format is simple. JSON capable of moving data between two interfaces with a very fast and powerful (eg between php with JavaScript).

JSON format is independent for any programming language, JSON have a simple structure so it can easily implemented. JSON requires less space and doesn't need to be written with the complete like XML. So logically it is faster in data processing (parsing).

\subsection{Web Service}

Web service is a software system which designed to support interoperability for machineto-machine interaction over a network. Web Service stores data information in XML format, so that this data can be accessed by other systems, although it have different platforms, operating systems, compilers and languages. Web service also allows to be called by using other protocol such as SMTP (Simple Mail Transfer Protocol), but the most commonly used by web services is HTTP. Web Services can be defined as an application that is accessed by another application (I Wayan Gede Wijaya Suma, 2012 ). [4] The Figure 1 below is an illustration of a web service.

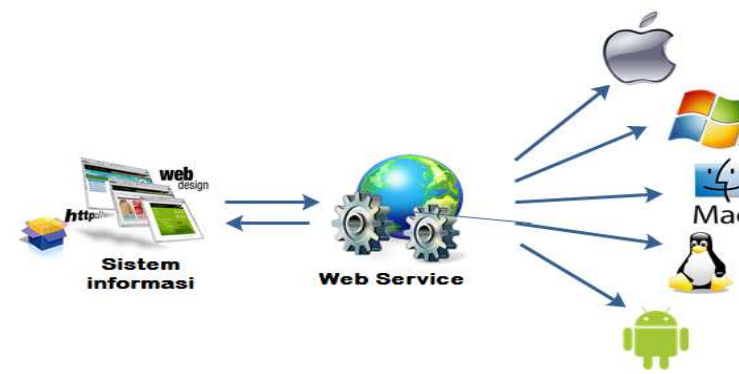

Fig 1. An application can be accessed by the variety of platforms using web service

\subsection{Moodle}

Moodle stands for Modular Object-Oriented Dynamic Learning Environment, which means a place of dynamic learning by using the objectoriented model. Moodle supports distributed learning packages in SCORM format (Shareble Content Object Reference Model). SCORM is a standard distribution of electronic learning package that can be used to accommodate a variety of learning material formats, either in the form of text, animation, audio and video [5].

\section{Design of The System}

In this study, the system was built based on Moodle and Android. The concept was being discussed here is the communication between client applications that are embedded on Android devices to a database server using a web service. The figure 2 is an overview of the applications design built on this study, where the client with Android devices have to access the internet over the database server through an intermediary server PHP.

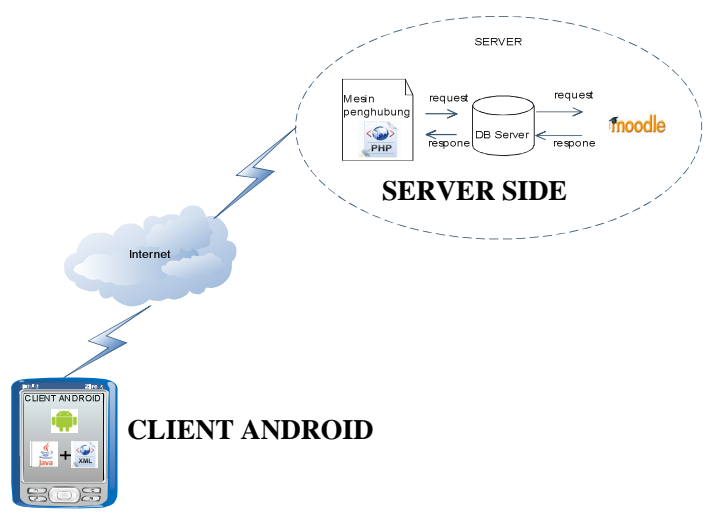

Fig 2. Scenario Design of Streaming Education Application on Android Based Mobile Device.

\subsection{Use Case Design}

Use Case diagram illustrates the expected functionality of a system. The emphasis is on "what" is done for the system, and not the "how". A use case represents an interaction between the actors in the system

Use case diagram for the research system consists of 8 use case and 2 actors. Actors students can see the material (text, / video), tasks, and task value. Guests can only view the subject material (text / video) and to download a course that has been permitted for them. Use case update assignment is an extension from use case submit assignments because students can choose if they want to change the tasks that have been collected during the task has not locked or expired. Use 
case diagrams of the Streaming Mobile Education system based on Android can be seen in Figure 3.

\subsection{Class Diagram}

Class diagram illustrates the Visualization class structure of the system. Classes have attributes and methods or operations. Class diagram describes the types of objects in the system and any various static relationships between them. Class diagram also shows the properties and operations of a class and the restrictions that contained in the object relations.

Class diagram for Streaming Mobile Education system consists of 15 classes. Classroom course is a generalization of the downloads, streaming video, tasks, assignments and news value class. The figure 4 is an illustration of the system class diagram.

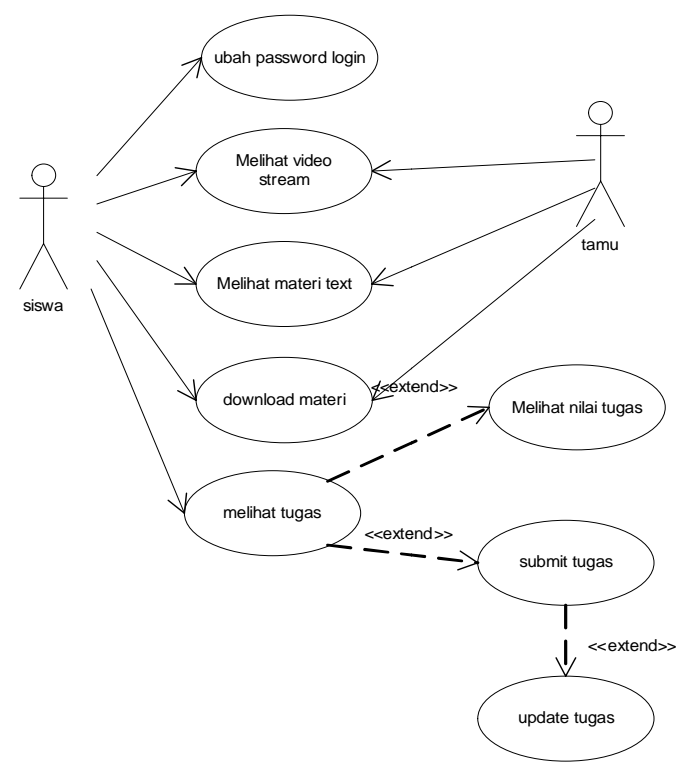

Fig 3. Use case diagram of Streaming Education Application on Android Based Mobile Device.

\subsection{Design of The Database}

The database used in this research is contained in the Moodle database with MySQL engine. The tables required in the system is 14 tables there are: table mdl_user, mdl_role, mdl_role_assignment, mdl_course_display, mdl_assignment_submissions,

mdl_course_modules,

mdl_assignment, mdl_forum,

mdl_forum_discussions, mdl_course_sections, mdl_resource, mdl_course, mdl_context and mdl_course_categories. [6]

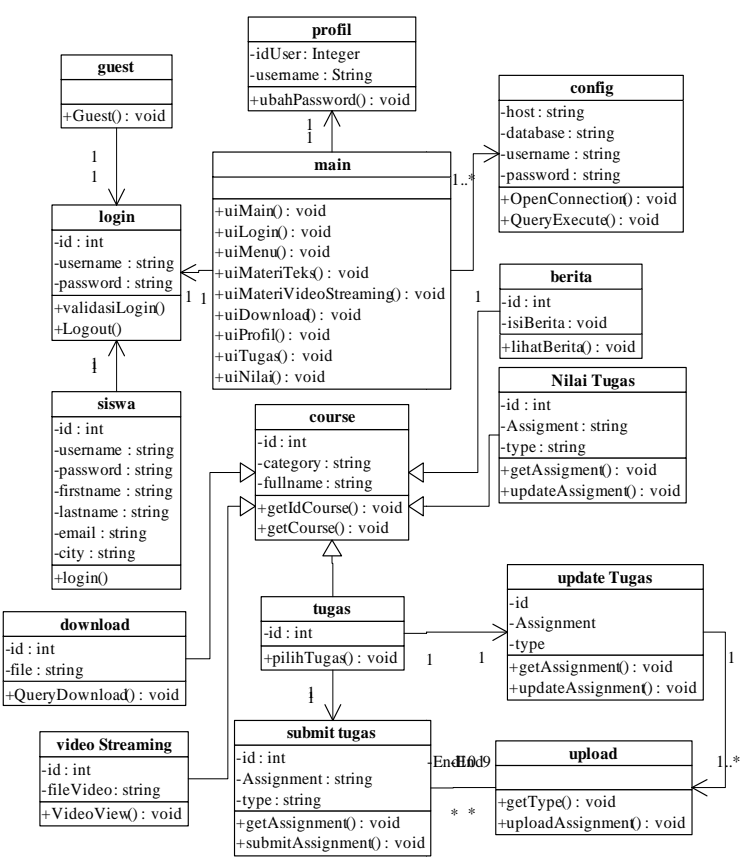

Fig 4. Class Diagram of Streaming Education Application on Android Based Mobile Device.

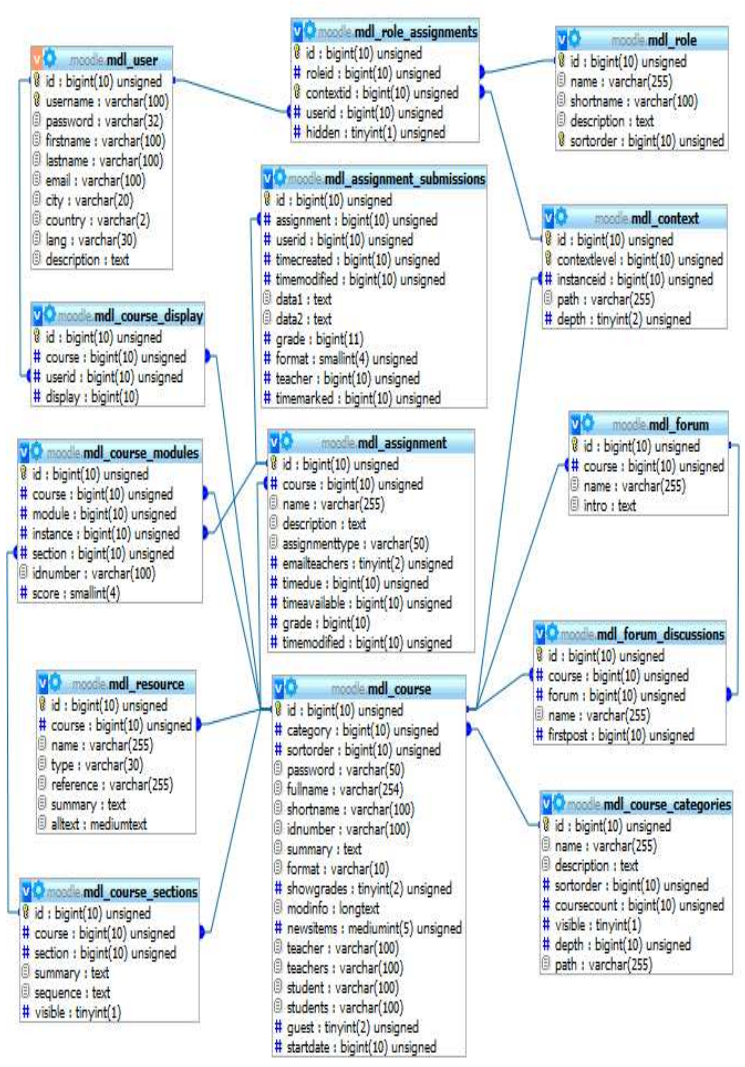

Fig 5. The Relations between tables in the Moodle database used of Streaming Education Application on Android Based Mobile Device 


\subsection{Design of The Appearance}

The Android screen used in this study were using XML. The Scroll View Components is used as the parent of the whole component. Scroll view have function to make the limited screen to be filled by the component which have the length or width exceeds of the screen size.

Inside the Scroll View there are several Relative Layout components as the parent layout of other components, such as buttons, textview and so on. The hierarchy of design layout for the system in this study can be seen in the Figure 6.

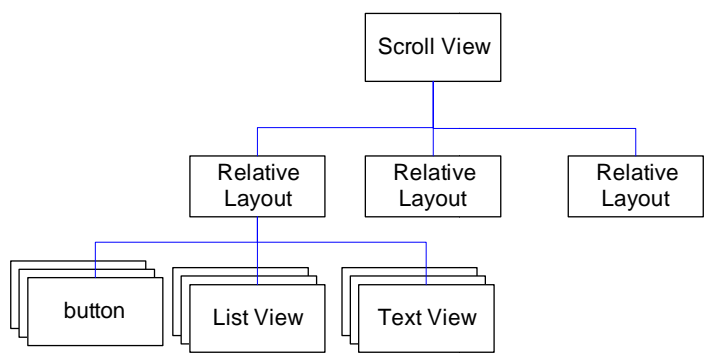

Fig 6. Appearance Design of Layout Hierarchy.

\section{Run Test of The Developed System}

This section discusses about testing the system functions that contained in the Mobile Streaming Education based on Android application. The testing is take part in the Android client side.

\subsection{Simulation Parameters}

The testing conducted on Android emulator using Eclipse Galileo IDE software specification, Android sdk 2.2, mysql database server, Windows 7 Professional operating system. And for the hardware using a notebook with AMD Athlon Neo Processor 1.6 GHz, 2 GB memory, $250 \mathrm{~GB}$ hard drive. Tests conducted using http://192.168.51.1/mobile server address. The indicator that the system has been running well there is no error message (force close) when the application is run. Section 4.2 shows the Streams Mobile Education application testing which accessed through Android emulator.

\subsection{Results}

The Figure 7 is an application display on the Android menu. Once the application icon Mobile Streaming Education (MSE) on the Android menu is clicked it will show the login view. The Figure 8 bellow shown the login screen on the Mobile Streaming Education application. The users who are not registered also have accses to the application, but with limited access rights.
The Figure 9 is a display when the user successfully login. On this display there are the navigation menus to get to the other pages.

The Course page have function to display a list of courses that are taken by students. The XML parsing technique were used to display the data contained on this page. Data retrieved from the Moodle database by PHP file conector. The Course List can be seen in the Figure 10.

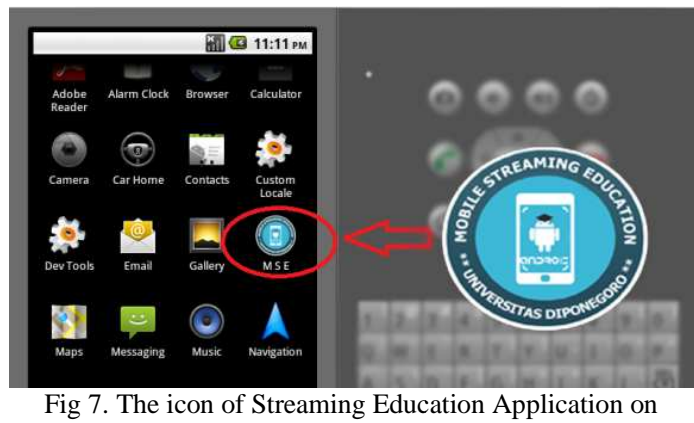

Android Based Mobile Device on the Android menu.

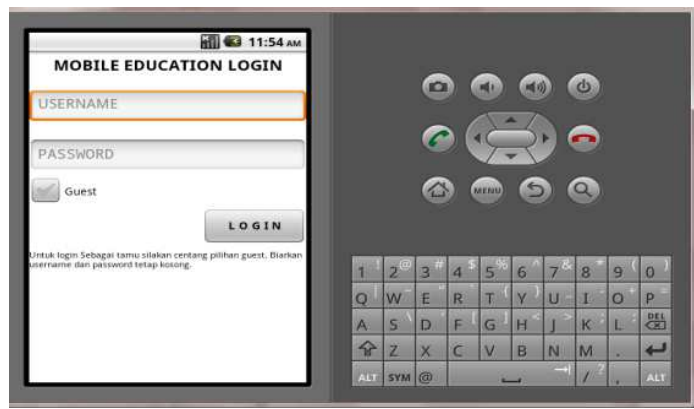

Fig 8 . The login page display of the developed system.

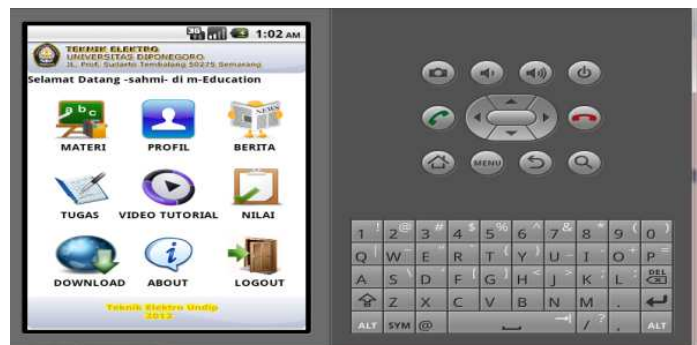

Fig 9. The main page display of the Streaming Education Applications on Android Based Mobile Device.

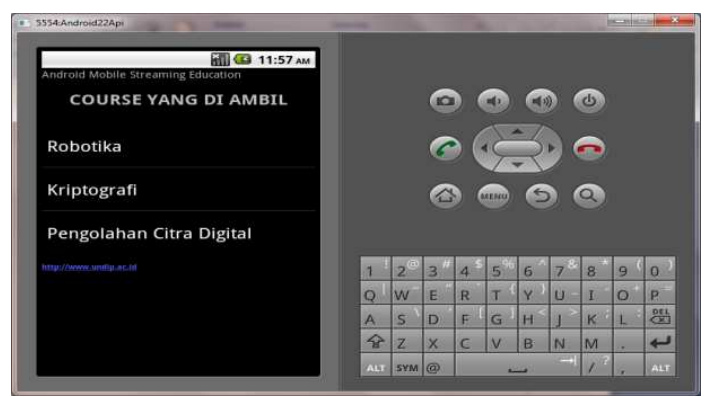

Fig 10. The menu course display of Streaming Education Application on Android Based Mobile Device. 
Course contents can be displayed by using JSON technique. Text retrieved from database tables mdl_ resource where contained in the database server. Course material content display can be seen in teh figure 11 .

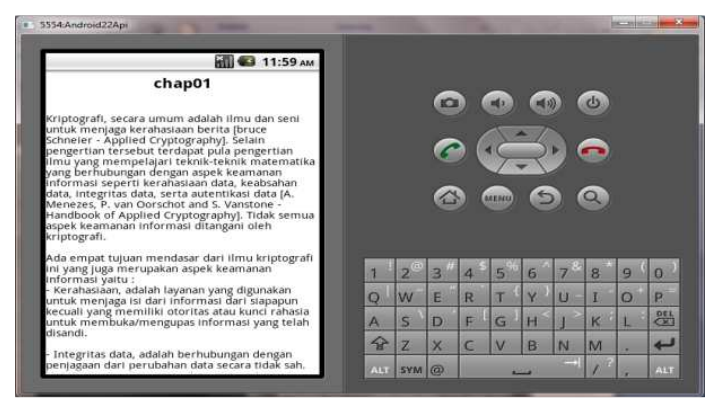

Fig 11. The course content display of Streaming Education Application on Android Based Mobile Device.

The Streaming function on this application can display a $3 \mathrm{gp}$ video format, the video which stored on databases server have a link address. Address of the video there is a link in the table mdl_resource. The video screen can be seen at the figure 12 .

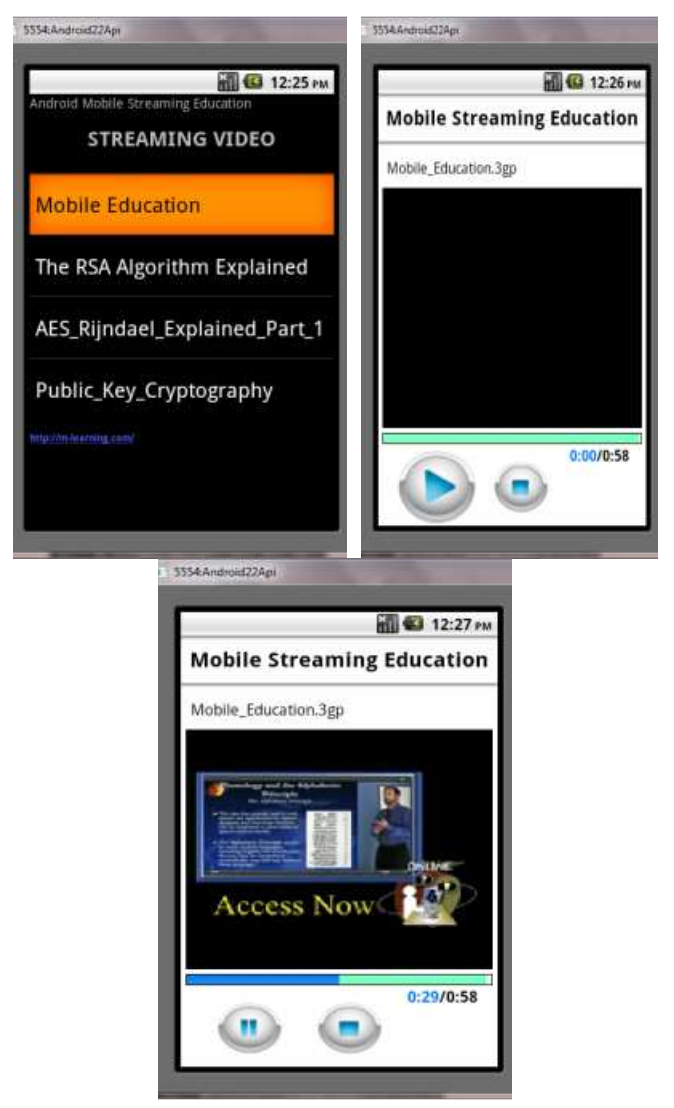

Fig 12. The video streaming display of Streaming Education Application on Android Based Mobile Device.
There are two types of tasks contained in the systems, submit text and upload files. User can submit text, the answers will go directly to the database, and if the task need to be uploaded, the file will be saved in the folder that contained the data on the server side. If the type of tasks is a text, the upload button will be disable, and vice versa. The Task screen can be seen in Figure 13.

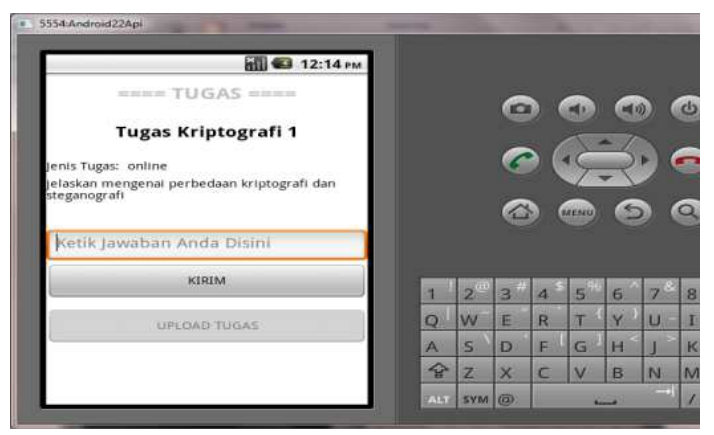

Fig 13. The assignment form display Streaming Education Application on Android Based Mobile Device.

\subsection{Analysis}

This section describes the analysis of the implementation of the Education Streaming on mobile devices based on Android. Analysis conducted on the functions of an application that built for the streaming and online education. These facilities include a menu to send and receive assignments, view grades assignments, streaming video and downloading course material.

Analyses were also conducted on the concept of Android programming technology that is used for the system development. Those analysis take part on the client and server communication paradigm using the web service.

Mobile Streaming Education based on Android is an applications on mobile devices for educational support. MSE application on the client side (which is installed on Android device) can work well when trying to access Moodle server database. The server in this research uses a local network with addresses at 192.168.51.1/mobile.

The web service successfully applied to the applications that have been built, by using JSON as a data exchange format that allows crossplatform without depending on the type of the application that were used on the client side.

In the real condition at the college, student can have varying subject, in this proposed application, the category of subjects that appear in each menu have been appropriate to the choice of courses from each student. Material text can also be displayed by using JSON. 
There are two mechanisms to deliver tasks in the application, which are send new tasks and update tasks. Tasks that have been sent can be updated as long as the task hasn't been closed. The system also has two type of task, which are text and files. Task of text will be submitted into the database and the file task will be submitted into the file storage folder on the server resource.

The streaming video material was able to play the video in $3 \mathrm{gp}$ format. The video material can be played parallel with the buffering process, so people could watch videos with long duration; user doesn't need to wait until the download is complete.

\section{Conclusion}

Although on the development of this system were using the Android Froyo SDK version 2.0.1, but the application can be run on Android version 2.3.7. Applications also can stream video in $3 \mathrm{gp}$ format with have video size $320 \times 240$ pixels.

The display of this application is designed for the devices which have screen size of 3.2 inches. On a device with a smaller screen size the applications display were truncated and scrollbar will appear. Application display become larger and does not change its composition when used on the larger screen size of 3.2 inches. Numbers of parameters that can be passed using XML parsing techniques in this study are four parameters for each file connection.

The study was conducted successfully sending a text using JSON parsing techniques (Javascript Object Notation) with a length of 405 characters of data. Length of characters that can be sent in this research is a medium text (16777215 characters).

The system still needs refinement. For further development, the menus such as course material, download, assignment, score, and streaming video can be combined to a compact course category. It will make an easier navigation. On the Android programming, Before starting to write the code java program, the programmers should create a design layout first, so each component of the XML object be able to recognized by Java compiler.

\section{Acknowledgment}

Part of this research is funded by Grant of Communication \& Signal Processing Laboratory. Diponegoro University, Semarang, 2012.

\section{References}

[1] Davidson, G.V,. \& Rasmussen, K.L. Web based learning: designing, implementation, and evaluation. Upper Saddle River, NJ: Pearson Education, Inc. 2006.

[2] Brown Quincy et al. The Design of a Mobile Inteligent Tutoring System. Drexel University. 2008.

[3] Robby Robson. Mobile Learning and Handheld Devices in the Classroom. Eduworks Corporation. Corvallis, Oregon, USA. 2003.

[4] I Wayan Gede Suma Wijaya. Penerapan Web Service pada Aplikasi Sistem Akademik pada Platform Sistem Operasi Mobile Android. Teknik Informatika, STIKOM PGRI Banyuwangi. Banyuwangi. 2012.

[5] Ahmadi C, dkk. Aplikasi Mobile Learning Berbasis Moodle dam MLE pada Pembelajaran Kedokteran Oos M. Anwas. Model inovasi E-Learning dalam Meningkatkan Mutu Pendidikan. Jurnal Teknodik. 2003.

[6] Android Developer, 2012. MySQL Documentation:MySQL Reference Manuals, Available at : http://developers.Android.com/ [28 September 2012]. 